\title{
Mathematical modeling of the air dehumidification using Peltier modules
}

\author{
Felipe N. Russo*, Harrson S. Santana, Kaciane Andreola and Osvaldir P. Taranto.
}

\begin{abstract}
In the food industries, the agglomeration process is used to improve the food powder characteristics, providing a shorter wetting time, for example, and consists in the growth of the particle size. Fluidized beds are commonly used in this process. However, an important aspect in this process is the fluidization gas humidity, in this case the atmospheric air humidity, which interferes directly in the agglomeration efficiency. Therefore, before entering the agglomeration process the air passes through a dehumidifying unit to decrease the air humidity. These units usually utilize water for dehumidification, but Peltier modules can substitute the cooling fluid. This work presents a mathematical model of the air dehumidification process using Peltier modules.
\end{abstract}

\section{Key words:}

Dehumidification, Peltier module, Mathematical modeling.

\section{Introduction}

In the agglomeration process in fluidized bed the fluidization air humidity can direct interfere in the process efficiency and the product quality. Therefore, before entering the process, the air must pass through a dehumidification unit so its relative humidity is within the acceptable limits for the process. In this unit, Peltier modules can be used to remove the humidity. This work has as its main objective to present a mathematical modeling to determine how much heat must be removed to dehumidify as well as the Peltier module's capacity of exchanging heat.

\section{Results and Discussion}

In order to determine which module model to be used, as well as how many modules are necessaries to dehumidify, firstly the amount of heat to be removed must be calculated by the sum of the sensible heat (Eq. 1), responsible for the air temperature decrease, and the latent heat (Eq. 2), present when the air gets to the saturation condition and water condensation starts:

$\dot{\mathrm{q}}_{\mathrm{s}}=\dot{\mathrm{m}} \mathrm{Cp}\left(\mathrm{T}_{1}-\mathrm{T}_{2}\right)$

$\dot{\mathrm{q}}_{\mathrm{L}}=\mathrm{h}_{\text {vap }}\left(\mathrm{Y}_{1}-\mathrm{Y}_{2}\right)$

In which $\dot{m}$ refers to the mass flow, $h_{\text {vap }}$ to the water vaporization enthalpy, $T_{1}$ and $T_{2}$ to the air inlet and outlet temperatures, and $Y_{1}$ and $Y_{2}$ to the system inlet and outlet humidity. Considering $50 \%$ as the maximum relative humidity at ambient temperature and with support of a psychrometric chart, it is possible to find the two operation points and calculate the heat, resulting in $60 \mathrm{~W}$ of heat to be removed, and pointing that the air must be cooled to 15 oc.

To determine how much heat can a Peltier module exchange, the following mathematical modeling was used to describe the system:

$\mathrm{q}_{\mathrm{a}}-\alpha_{\mathrm{m}} \mathrm{T}_{\mathrm{a}} \mathrm{I}=-\frac{\mathrm{T}_{\mathrm{e}}-\mathrm{T}_{\mathrm{a}}}{\theta_{\mathrm{m}}}-\frac{\mathrm{I}^{2} \mathrm{R}_{\mathrm{m}}}{2}$

$\mathrm{V}=\mathrm{I} \mathrm{R}_{\mathrm{m}}+\alpha_{\mathrm{m}} \Delta \mathrm{T}$

In which $q_{a}$ is the heat removed by the module's cold side, $T_{a}$ and $T_{b}$ are the cold and hot side temperatures and the parameters $R_{m}, \theta_{m}$ e $\alpha_{m}$ are calculated with the fabricant data. The following results were obtained utilizing the model HTC-50-12-15.4.

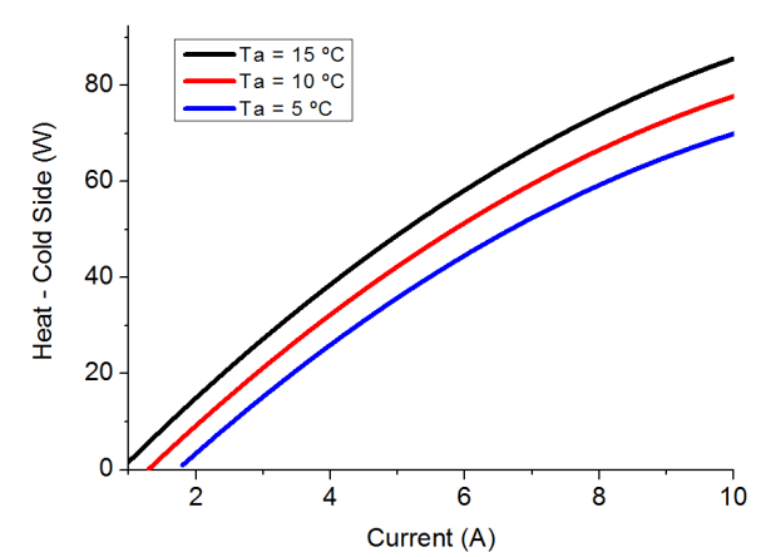

Image 1. Variation on the heat exchange for different values of $\mathrm{T}_{\mathrm{a}}$ for the model HTC-50-12-15.4.

Chart 1. Values of the heat exchanged and the number of modules necessaries corresponding to each current value, with $\mathrm{T}_{\mathrm{a}}=15^{\circ} \mathrm{C}$

\begin{tabular}{|c|c|c|}
\hline Current $(\mathrm{A})$ & Heat $(\mathrm{W})$ & $\begin{array}{c}\text { Number of } \\
\text { Peltier modules }\end{array}$ \\
\hline 1 & 1,7 & 36 \\
\hline 2 & 14,9 & 5 \\
\hline 3 & 27,3 & 3 \\
\hline 4 & 38,6 & 2 \\
\hline $\mathbf{5}$ & $\mathbf{4 8 , 9}$ & $\mathbf{2}$ \\
\hline
\end{tabular}

\section{Conclusions}

The Peltier modules unit can remove the $60 \mathrm{~W}$ required from the fluidization air, taking it from saturation conditions at ambient temperature, found on rainy days, for example, to $40 \%$ relative humidity at the same temperature. To accomplish that, it is required a $6 \mathrm{~A}$ current. In currents below this value, it is necessary to use several modules. In $4 \mathrm{~A}$ and $5 \mathrm{~A}$ two Peltier modules are required to achieve the heat removed from $60 \mathrm{~W}$.

\section{Acknowledgement}

The authors would like to thank the support given by CAPES and CNPq. 